\title{
Frustration Level of High School Students among Their Gender
}

\author{
Muddanagouda Patil ${ }^{1 *}$, Dr. Shivakumara $\mathrm{K}^{2}$
}

\section{ABSTRACT}

The present study aimed to assess the Frustration level of high school students among their gender in relation to their Montessori and Traditional method of education. It was hypothesized that male and female high school students of Montessori education and Traditional education have significant difference on Frustration level. In order to verify the above hypotheses a sample of 120 students were selected from high schools which offer education with Montessori $(\mathrm{N}=60)$ and Traditional methods $(\mathrm{N}=60)$ include equally male and female students. To measure variable the Frustration scale was used which is developed and standardized by Chauhan \& Tiwari (1999). This scale administered individually on the subjects. The data were subjected to ' $t$ ' analyses and the major findings of the study revealed that following are dawn:

1. The male and female students of Montessori education obtained ' $t$ ' value is 0.80 , which is not significant level.

2. The male and female students of Traditional education obtained ' $t$ ' value is 2.19, which is significant at 0.05 level.

3. There is no significant difference between the male students of Montessori and Traditional education. The obtained ' $t$ ' value is 1.11 , which is not significant level.

4. There is significant difference between female high school students of Montessori and Traditional education. The obtained 't' value is 2.98, which is highly significant at 0.01 level.

Keywords: Gender, Frustration Montessori and Traditional Method of Education.

Freud (1943) developed the concept of frustration first time in human beings. According to Freud, "frustration occurs whenever pleasure seeking or pain-avoiding behaviour is blocked". He established a causal relationship between frustration and aggression. With the work of Freud, several theories of frustration have appeared during the late 1930's and 1940's. These theories propounded 4 modes of frustration such as-regression, resignation, fixation and aggression.

\footnotetext{
${ }^{1}$ Research Scholar, Department of Psychology, Karnatak University Dharwad

2 Associate Professor, Department of Psychology, Karnatak University Dharwad

*Responding Author

(C) 2016 I M Patil, S Kumara; licensee IJIP. This is an Open Access Research distributed under the terms of the Creative Commons Attribution License (http://creativecommons.org/licenses/by/2.0), which permits unrestricted use, distribution, and reproduction in any Medium, provided the original work is properly cited.
} 


\section{Frustration Level of High School Students among Their Gender}

Encyclopedia of Psychology (1951) defines, "frustration is any interference with a goal response or with the instrumental acts leading to it”.

Whereas, the Oxford Advanced Learner's Dictionary (2000) defines, "Frustration is the feeling that makes somebody feels annoyed or impatient because they cannot do or achieve what they want”.

"Frustration refers to the blocking of behaviour that is directed towards a goal" (Robinson, 1961; Murphy, 1964; Coleman, 1964; Kretch\& Crutchfield, 1965). Frustration is 'motivational or affective state resulting from being blocked, thwarted, disappointed or defeated' (English and English, 1959), has a different mechanism of behaviour, lacking goal-orientation, having feeling of intensity, compulsiveness, appearing a product of need-deprivation (Chauhan \& Tiwari, 1972).

Davitz (1942) defined frustration as the blocking of drive evoked behaviour, thwarting of a need or desire (Coleman, 1971). It exists when a goal response suffers interference (Dollard et al., 1939). When the individual seek to attain a goal and finds that his way to the goal is blocked by an obstacle or a barrier, tension is produced and it lasts as long as the barrier is present. Every individual tries removing these barriers or obstacles, but frustration occurs only when the organism is unable to remove the hindrances. So in frustrtion motivated behaviour of the individual is blocked and he is unable to remove the insurmountable barrier, that's why underlying tension resolves and results into frustration.

\section{Frustration-Regression Theories:}

In Freudian term, regression means a return to earlier mode of adjustment. Operationally regression may be defined in terms of a behaviour characterized by bashfulness, being finicky about foods, lack of self-control, homesick when away from home, crying easily, defective speech, excessive day-dreaming, exorbitantly ambitious etc.

According to one interpretation, regression indicates that the individual attempts to return to past security from the present midst of insecurity. Regression is the end response of frustration (Barker et al., 1941). Regression may be defined as an ego-defense mechanism in which 'the individual retreats to the use of less mature responses in attempting to cope with stress and maintain ego integrity' (Coleman, 1971). Here an individual emphasizes on the superior joys of 'the good old days' so it has been called the 'old oaken bucket' delusion. Previous satisfaction provides a mode of proper adjustment in regression so the individual takes help of this defense mechanism.

\section{Frustration-Resignation Theory:}

Resignation is an emotionally tinged attitude shown by cessation of active response to a situation which we have previously been making efforts to alter (Chauhan \& Tiwari, 1972). In resignated 


\section{Frustration Level of High School Students among Their Gender}

behaviour individual obtains extreme elimination of needs, no plans, no definite relations to the future, either no hope at all or hope which is not taken seriously.

The factors related to resignation type of behaviours are limitations of all needs, no plan, no definite relation to future, a withdrawal tendency from social contacts, frequent and serious consideration of committing suicide, longing for loneliness, no social type of hobby, retreatism, returning within one's self, day-dreaming, lack of interest in his surroundings etc.

\section{Frustration-Fixation Theory:}

Maier (1949) noted fixated behaviour tend to be repeated over and over again with out variations and shows a degree of resistance to change. Fixated behaviour as such remains compulsive. This compulsive and stereotyped pattern has been called an abnormal fixation. In this context Maier has put another theory of 'frustration-fixation' hypothesis, where behaviors become stereotyped and is persisted in despite consequences. The frustrated individual behaves more or less rigidly, compulsive in many activities and stereotyped. Fixative behaviour seriously blocks the acquisition of new forms of adjustment.

Fixated behaviour may be taken in terms of interests and emotional attitudes to designate the attachment generally interpreted to belong to an early stage of development. The fixated persons have a difficulty in forming new attachments developing new interest or adaptations (Chauhan \& Tiwari, 1972).

\section{Frustration-Aggression Theory:}

Freud emphasizes the study of aggression to understand human behaviour disorders. For Freud, aggression is one of the consequences of frustration. This suggestion of Freud widely accepted by Dollard et al., (1939), and formulated a theory and postulated that frustration results in aggression.

"Aggression has been defined as an act, whose goal response is injury to an organism or organism-surrogate” (Dollard et al., 1939). Aggression is defined as behavior intended to injure the person toward whom it is directed.

Yale group hypothesis of 'frustration-aggression' defined aggressive behaviour as logical and expected consequence of frustration. They state that when our efforts relate to the goal-directed behaviour suffers interference; our first reaction is often one of attacking and attempting to remove the obstacle (Dollard et al., 1939).

\section{Montessori Education:}

Montessori education is an education approach developed by Italian physician and educator Maria Montessori. Montessori education is practiced in an estimated 20,000 schools worldwide, serving children from birth to eighteen years old. This education is characterized by an emphasis 
on independence, freedom within limits, and respect for a child's natural psychological development, as well as technological advancements in society. Although a range of practices exists under the name "Montessori", the primary elements are;

- Mixed age classrooms, with classrooms for children 3 to 6 years old by fat the most common.

- Student choice of activity from within a prescribed range of options

- A constructivism or discovery model, where students learn concepts from working with materials, rather than by direct instruction

- Children are to be respected as different from adults and as individuals who differ from each other

- The child possesses an unusual sensitivity and intellectual ability, unlike those of the adult, to absorb and learn from his environment, both in quality and quantity

- The first six years of life are the most important years of a child's growth when unconscious learning gradually emerges to the conscious level

In the Montessori system of education, each child is a unique being. He is encouraged to develop social and emotional sills and body-mind coordination as well as cognitive preparations for future intellectual activities.

A method of schooling that focuses on personal development rather than exams produces more mature, creative and socially adept children, scientists have found. Psychologists in the US found that across a range of abilities, children at Montessori schools out-performed those given a Traditional education. Some of the biggest differences were seen in social skills and behaviour. Montessori children displayed a greater sense of "justice and fairness", interacted in an "emotionally positive" way, and were less likely to engage in "rough play" during break times.

The method discourages Traditional competitive measurements of achievement, such as grades and tests, and instead focuses on the individual progress and development of each child. The scientists concluded: "Montessori education fosters social and academic skills that are equal or superior to those fostered by a pool of other types of schools."

\section{City Montessori school (CMS) at Laknow, India:}

This school is very biggest school in the word. This school has bagged Guinness World Records awards the title to the City Montessori School (CMS) in Lucknow in the 2010-2011 academic years. The school has above 45000 students with 2500 teachers, 3700 computers, 1,000 classrooms and 1000 school bus.

Goal: True progress of humanity is impossible unless and until the goals to which education is geared are completely revised - with spiritual development at its centre, not as an add on at the margins of education. These new goals for education will free it from its largely economic context. This revises greatly our expectations of human potential and its outcome through education. The goal of education is to inspire every child to become both good and smart, a pride 
of the human race, a citizen of the world and a light of humanity. It defines education as a continuous and creative process.

Importance: importance to inner over outer aspects and taking practical measures that support these directions, a child can become a light of this world, serving her community in unique and creative ways, with a sense of purpose and motivation that comes from within. Knowledge, wisdom, spiritual perception and eloquent speech, with deeds not words as testimony, are Four Outcomes of a Broader, Bolder educational process. These are the most important outcomes from education.

'Spiritual understanding combined with reason expands a child's ability to better perceive, empathize and comprehend.' There is a natural connection between science and spirituality. Human beings are endowed with spiritual capacities.

\section{LITERATURE REVIEW}

Dollard et al., (1939) studied frustration and aggression in adolescence. The last important phase of maturation in the life of the individual and the last period of intensified socialization occurs at pubescence. It has been generally recognized that this period of adjustment is an especially critical one that produces many conflicts and typical behaviour patterns as a result of the efforts of adolescents to make adjustments to new physiological instigations and to learn the new habit patterns demanded by society. This interference with the redirection of drive-instigated behaviour is presumed to be frustrating and hence an increase of aggression at this time is to be anticipated. The authors examined in their article some of the facts of pubescence, to attempt to analyze the main frustrating situations, and to describe some of the resulting aggressive behaviour.

Bateson and Gregory (1941) studied the frustration-aggression hypothesis and culture. The necessity is pointed out for assuming that the frustration-aggression hypothesis refers simply to sequences of culturally modified acts. Two cultures are contrasted, the Iatmul of New Guinea, and the Balinese. The hypothesis fits the former perfectly, with the added modification that they have invested aggression with pleasure and convert all their cognitive efforts into imaginary aggressions. But the Balinese show no aggression reaction what so ever to interruptions of their acts. Only the children show signs of frustration and temper tantrums. They lose these later as a result of the unique relations in play between mother and child which discourage any goalexpectancy set.

Miller (1941) studied the frustration-aggression hypothesis. A previous statement in the book Frustration and aggression that "the occurrence of aggression always presupposes the existence of frustration and contrariwise frustration always leads to some form of aggression" is misleading in the latter half. A suggested reformulation is that "frustration produces instigations to a number of different types of response, one of which is instigation to some form of 
aggression." The determination of the presence of such instigation, when the overt behaviour is prevented, can be made by observing indirect or less overt acts. 4 chief lines of investigation suggested by the hypothesis are outlined.

Seashore and Bavelas (1942) studied frustration in children. 18 children, 9 of whom were cases of a child guidance clinic, repeatedly drew men for the Good enough test, under the observation of the experimenter and an assistant. After each performance the experimenter expressed implied criticism by asking the child to draw another "better" one, until the child had drawn 15 or refused to do more. 10 cases showed deterioration of performance, some drawings being unsociable. Changes in attitude, as shown by time spent on drawings and conversation, were marked. The implications of the findings are discussed and some of the protocols included.

Roger (1943) studied regression mode of frustration. The relation between regression and development is of special interest and significance. The indirect way of studying the dynamics of development by studying regression may prove to be fruitful for the whole problem of development. This chapter begins by describing the behaviour and state of the person corresponding to different developmental levels. Next, it reports an attempt to create regression in children by frustration. It can be viewed from two angles: (a) it is an attempt to clarify the nature of regression and the conditions leading to it by testing certain theoretical assumptions about regression. (b) It can be viewed as a contribution to the study of frustration.

Berkowitz and Leonard (1989) studied frustration-aggression hypothesis. The original formulation's main proposition is limited to interference with an expected attainment of a desired goal on hostile (emotional) aggression. Although some studies have yielded negative results, others support the core proposition. Frustrations can create aggressive inclinations even when they are not arbitrary or aimed at the subject personally. Interpretations and attributions can be understood partly in terms of the original analysis but they can also influence the unpleasantness of the thwarting. A proposed revision of the 1939 model holds that frustrations generate aggressive inclinations to the degree that they arouse negative affect.

\section{RESEARCH METHODOLOGY}

\section{Research problem:}

There is significant difference on Frustration level of high school students among gender in relation to their Montessori and Traditional method of education?

\section{Objective:}

- To explore the gender difference in Frustration level of high school students in relation to their Montessori and Traditional method of education. 


\section{Frustration Level of High School Students among Their Gender}

\section{Hypotheses:}

1. Male students of Montessori education have significantly higher level of Frustration than female students of Montessori education.

2. Male students of Traditional education have significantly higher level of Frustration than female students of Traditional education.

3. Male students of Traditional education have significantly higher level of Frustration than male students of Montessori education.

4. Female students of Traditional education have significantly higher level of Frustration than female students of Montessori education.

\section{Sample of the study:}

The study was conducted on 120 samples of high school students of Montessori and Traditional Method of education out of which 60 (30 male and 30 female) students studying in $8^{\text {th }}$ and $9^{\text {th }}$ standard were selected from Montessori method of education of Chandana High School, Sirasi and 60 (30 Boys and 30 Female) students in $8^{\text {th }}$ and $9^{\text {th }}$ standard with the age group of 12 to 16 years were selected from Karnataka University Public School located in Dharwad, Karnataka state.

\section{Tools of study:}

Frustration Test developed and standardized by Chauhan \& Tiwari (1999), has 40 items with 4 dimensions such as Fixation, Regression, Resignation and Aggression and each dimension has 10 items. Frustration following scoring pattern of 5, 4, 3, 2, 1 \& 0 . The test-retest reliability for the subscales of four modes of Frustration ranges from .78 to .92 and on total scale the reliability is .88. Where as validity of the scale is found to be significant level.

\section{Statistical Techniques:}

Obtained samples raw scores were converted into standard scores using 16.0 versions of SPSS, subsequently the mean and SD was calculated. The data was subjected to independent sample ' $\mathrm{t}$ ' analysis to find the significant difference between the boys and female of Montessori and Traditional Method of education. 


\section{RESULTS AND DISCUSSION}

Table no 01: Means, standard deviations and ' $t$ ' value of the male and female students of Montessori education on Frustration.

\begin{tabular}{|c|c|c|c|c|}
\hline \multirow{2}{*}{\multicolumn{2}{|c|}{ Frustration }} & \multicolumn{3}{|c|}{ Sample Group $(\mathrm{N}=60)$} \\
\hline & & \multirow{2}{*}{$\begin{array}{l}\text { Male Students of } \\
\text { Montessori education } \\
(\mathrm{N}=30) \\
46.37\end{array}$} & \multirow{2}{*}{$\begin{array}{l}\text { Female Students of } \\
\text { Montessori education } \\
(\mathbf{N}=\mathbf{3 0}) \\
49.46\end{array}$} & \multirow{3}{*}{$\frac{\text { 't' values }}{1.40^{\mathrm{NS}}}$} \\
\hline \multirow{2}{*}{ Regression } & Mean & & & \\
\hline & SD & 9.23 & 7.77 & \\
\hline \multirow{2}{*}{ Fixation } & Mean & 49.92 & 49.32 & \multirow{2}{*}{$0.27^{\mathrm{NS}}$} \\
\hline & SD & 9.03 & 7.89 & \\
\hline \multirow{2}{*}{ Resignation } & Mean & 44.95 & 50.15 & \multirow{2}{*}{$2.05^{*}$} \\
\hline & SD & 9.86 & 9.71 & \\
\hline \multirow{2}{*}{ Aggression } & Mean & 51.13 & 42.27 & \multirow{2}{*}{$4.01^{* *}$} \\
\hline & SD & 9.16 & 7.86 & \\
\hline \multirow{2}{*}{ Total Frustration } & Mean & 46.65 & 48.39 & \multirow{2}{*}{$0.80^{\mathrm{NS}}$} \\
\hline & SD & 8.91 & 7.73 & \\
\hline
\end{tabular}

NS: Not significant. *Significant at 0.05 level. **Significant at 0.01 level

The table no 01 shows means, standard deviations and 't' value of the male and female students of Montessori education on Frustration. The Regression and fixation mode of Frustration there is no significant difference between male and female students of Montessori education. The obtained ' $t$ ' value for the mean difference are respectively 1.40 and 0.27 which is significant level. On the Resignation and Aggression mode of Frustration there is significant difference between male and female students of Montessori education. The obtained ' $t$ ' value for the mean difference are respectively 2.05 which is significant at 0.05 level and 4.01 which is highly significant at 0.01 level. Further result found that, on the total Frustration the female students of Montessori education mean score of 48.39 then the male students of Montessori education $(\mathrm{M}=46.65)$. The obtained ' $\mathrm{t}$ ' value for the mean difference is 0.80 which is not significant level. 
Table no 02: Means, standard deviations and ' $t$ ' value of the male and female students of Traditional education on Frustration.

\begin{tabular}{|c|c|c|c|c|}
\hline & & \multicolumn{3}{|c|}{ Sample Group $(\mathrm{N}=60)$} \\
\hline \multicolumn{2}{|l|}{ Frustration } & $\begin{array}{l}\text { Male Students of } \\
\text { Traditional } \\
\text { education }(\mathrm{N}=30)\end{array}$ & $\begin{array}{l}\text { Female Students of } \\
\text { Traditional education } \\
(\mathrm{N}=30)\end{array}$ & 't' values \\
\hline \multirow{2}{*}{ Regression } & Mean & 49.65 & 54.53 & \multirow{2}{*}{$1.76^{\mathrm{NS}}$} \\
\hline & SD & 11.56 & 9.77 & \\
\hline \multirow{2}{*}{ Fixation } & Mean & 47.11 & 53.68 & \multirow{2}{*}{$2.30 *$} \\
\hline & SD & 11.62 & 10.45 & \\
\hline \multirow{2}{*}{ Resignation } & Mean & 50.55 & 54.49 & \multirow{2}{*}{$1.60^{\mathrm{NS}}$} \\
\hline & SD & 8.28 & 10.16 & \\
\hline \multirow{2}{*}{ Aggression } & Mean & 53.57 & 53.05 & \multirow{2}{*}{$0.21^{\mathrm{NS}}$} \\
\hline & SD & 9.43 & 9.48 & \\
\hline \multirow{2}{*}{$\begin{array}{l}\text { Total } \\
\text { Frustration }\end{array}$} & Mean & 49.48 & 55.49 & \multirow{2}{*}{$2.19 *$} \\
\hline & SD & 10.72 & 10.50 & \\
\hline
\end{tabular}

NS: Not significant. *Significant at 0.05 level.

The table no 02 shows means, standard deviations and ' $t$ ' value of the male and female students of Traditional education on Frustration. The Regression, Resignation and Aggression mode of Frustration there is no significant difference between female students of Traditional education and male students of Traditional education. The obtained ' $t$ ' value for the mean difference are respectively 1.76, 1.60, and 0.29. On the Fixation mode of Frustration the female students of Traditional education have higher mean score of 53.68 than the male students of Traditional education ( $\mathrm{M}=47.11)$. The obtained ' $\mathrm{t}$ ' value for the mean difference is 2.30 , which is significant at 0.05 level. Total Frustration the female students of Traditional education have higher mean scores of 55.49 than the male students of Traditional education $(M=49.48)$. The obtained ' $t$ ' value is 2.19, which is significant at 0.05 level. This shows that the female students have higher Frustration than the male students of Traditional school. 
Table no 03: Means, standard deviations and ' $t$ ' value of the male students of Montessori and Traditional education on Frustration.

\begin{tabular}{|c|c|c|c|c|}
\hline \multirow{2}{*}{ Frustration } & & \multicolumn{3}{|c|}{ Sample Group $(\mathrm{N}=60)$} \\
\hline & & $\begin{array}{l}\text { Male students of } \\
\text { Montessori education } \\
(\mathrm{N}=30)\end{array}$ & $\begin{array}{l}\text { Male students of } \\
\text { Traditional } \\
\text { education( } N=30)\end{array}$ & ' $t$ ' values \\
\hline \multirow{2}{*}{ Regression } & Mean & 49.65 & 54.53 & \multirow{2}{*}{$1.21^{\mathrm{NS}}$} \\
\hline & SD & 11.56 & 9.77 & \\
\hline \multirow{2}{*}{ Fixation } & Mean & 47.11 & 53.68 & \multirow{2}{*}{$1.04^{\mathrm{NS}}$} \\
\hline & SD & 11.62 & 10.45 & \\
\hline \multirow{2}{*}{ Resignation } & Mean & 50.55 & 54.49 & \multirow{2}{*}{$2.38 *$} \\
\hline & SD & 08.28 & 10.16 & \\
\hline \multirow{2}{*}{ Aggression } & Mean & 53.57 & 53.05 & \multirow{2}{*}{$1.01^{\mathrm{NS}}$} \\
\hline & SD & 09.43 & 9.48 & \\
\hline \multirow{2}{*}{ Total Frustration } & Mean & 49.48 & 55.49 & \multirow{2}{*}{$1.11^{\mathrm{NS}}$} \\
\hline & SD & 10.72 & 10.50 & \\
\hline
\end{tabular}

NS: Not significant. *Significant at 0.05 level.

The table 03 shows means, standard deviations and ' $\mathrm{t}$ ' values of the male students of Montessori and Traditional education on Frustration. On Resignation, Fixation and Aggression mode of Frustration there is no significant difference between the male students of Montessori and Traditional education. The obtained ' $t$ ' value for the mean difference are respectively 1.21, 1.04 and 1.01 which is not significant level. The Resignation mode of Frustration the male students of Traditional education have higher mean score of 50.55 than the students of Montessori education $(\mathrm{M}=44.95)$. The obtained ' $\mathrm{t}$ ' value for the mean difference is 2.38 , which is highly significant at 0.05 level. On the total of Frustration there is no significant difference between the male students of Montessori and Traditional education. The obtained mean scores are 46.65 and 49.48 respectively. The ' $t$ ' value obtained for the mean difference is 1.11 , which is not significant. 
Table no 04: Means, standard deviations and 't' value of the female students of Montessori and Traditional education on Frustration.

\begin{tabular}{|c|c|c|c|c|}
\hline \multirow{2}{*}{ Frustration } & & \multicolumn{3}{|c|}{ Sample Group $(\mathrm{N}=60)$} \\
\hline & & $\begin{array}{l}\text { Female Students of } \\
\text { Montessori education } \\
(\mathrm{N}=30)\end{array}$ & $\begin{array}{l}\text { Female Students of } \\
\text { Traditional education } \\
(\mathrm{N}=30)\end{array}$ & 't' value \\
\hline \multirow{2}{*}{ Regression } & Mean & 49.46 & 54.53 & \multirow{2}{*}{$2.22 *$} \\
\hline & SD & 07.77 & 09.77 & \\
\hline \multirow{2}{*}{ Fixation } & Mean & 49.32 & 53.68 & \multirow{2}{*}{1.82} \\
\hline & SD & 07.89 & 10.45 & \\
\hline \multirow{2}{*}{ Resignation } & Mean & 50.15 & 54.39 & \multirow{2}{*}{1.64} \\
\hline & SD & 09.71 & 10.16 & \\
\hline \multirow{2}{*}{ Aggression } & Mean & 42.27 & 53.05 & \multirow{2}{*}{$4.79 * *$} \\
\hline & SD & 07.86 & 09.48 & \\
\hline \multirow{2}{*}{ Total Frustration } & Mean & 48.39 & 55.49 & \multirow{2}{*}{$2.98^{* *}$} \\
\hline & SD & 07.73 & 10.50 & \\
\hline
\end{tabular}

* Significant at 0.05 level. ** Significant at 0.01 level.

The table no 04 shows means, standard deviations and ' $t$ ' value of the female students of Montessori and Traditional education on Frustration. The Fixation and Resignation mode of Frustration there is no significant difference between the female students of Montessori and Traditional education. The obtained ' $t$ ' value for the mean difference are respectively 1.82 and 1.64 which is not significant. The dimensions Regression and Aggression of frustration the female students of Traditional education have higher mean score than the female students of Montessori education. The obtained ' $t$ ' value for the mean difference are respectively 2.22 which is significant at 0.05 level and 4.79 which is highly significant at 0.01 level. On the total of Frustration the female students of Traditional education have higher mean score of 55.49 than the female students of Montessori education $(\mathrm{M}=48.39)$. The obtained ' $t$ ' value is 2.98 which is highly significant at 0.01 level. This shows that the Traditional education students have higher Frustration than the students of Montessori education.

\section{SUMMARY}

The present study is an attempt to know the level of frustration of the high school students among their gender in relation to their Montessori and Traditional method of education. The sample of the present study consisted of 120 high school children including both male female. Of them, 60 students (30 male and 30 female) selected from Montessori method school and 60 students (30 male and 30 female) were selected from Traditional. For measuring frustration used the Frustration Scale developed and standardized by Chauhan \& Tiwari (1972).

\section{CONCLUSIONS}

- There is no significant difference on frustration between the male students of Traditional education and Montessori education. 
- The female students of tradition education have significantly higher level of frustration than the female students of Montessori education.

- The male students of Montessori education have significantly higher frustration than the female students of Montessori education.

- The female students of Traditional education have significantly higher frustration than the male students of Traditional education.

\section{LIMITATIONS OF THE STUDY}

- More than one school in each of the category of Montessori and Traditional method of education should have been taken for the study.

- The sample size is smaller in each of the subgroups.

- Instead of purposive sampling other methods of randomization should have been adopted.

\section{REFERENCE}

Baker J, Schaie K. Effects of aggressing "alone" or "with another" on physiological and psychological arousal. Journal of Personality and Social Psychology. 1969;12:80-86.

Bateson and Gregory (1941). The frustration and aggression hypothesis and culture. Psychological Review, 48 (4), 350-355.

Berkowitz, L. (1993). Aggression - Its Causes, Consequences, and Control. New York.

Berkowitz, Leonard. 1989. Frustration-aggression hypothesis: Examination and reformulation. Psychological Bulletin, 106 (1), 59-73.

Buunk, B. P., Angleitner, Oubaid, V., \& Buss, D. M. (1996).Sex differences in jealousy in evolutionary and cultural perseptive, test from the Netherlands, Germany, and the United States.Journal of Psychological science, 7(6), 359-362.

Chauhan NS, Tiwari GP. Manual of frustration scale. Agra: Agra Psychological Cell; 1972.

Coleman JC. Psychology and effective behaviour. Bombay: Taraporewale; 1971.

Colman, A. M. (2009) A Dictionary of Psychology. 3rd edn, Oxford: Oxford University Press.

Dollard J, Doob LW, Miller NE, Mowrer OH, Sears RR. Frustration and aggression. New Haven, CT: Yale University Press; 1939.

Dollard, J., Doob, L. W., Miller, N. E., Mowrer, O. H., \& Sears, R. R. (1939). Frustration and aggression.New Haven, CT: Yale University Press.

Dollard, Miller, Leonard, and Mowrer.(1939). Frustration and aggression in adolescence. New haven, CT, US, Yale University press, 8, 213.

Ellen, Bassuk, m. d., Lenore, Rubin, ph.d. (1987). Homeless children: neglected population. American Journal of Orthopsychiatry, 57(2), 279-286.

Encyclopedia of Psychology. New York: Citadel Press; 1951.

English HB, English, AC. A comprehensive dictionary of psychological and psychoanalytical terms. Longmans; 1959.

Freud S. A general introduction to psychoanalysis, New York: Garden City Publishing Company; 1943. 
Freud, A. (1937) The Ego and the Mechanisms of Defence, London: Hogarth Press and the Institute of Psychoanalysis.

Freud, S. (1914) On the History of the Psycho-Analytic Movement, Penguin Freud Library, vol. 15, Harmondsworth: Penguin.

Freud, S. (1915) Instincts and their Vicissitudes. Standard edn. vol. 14, London: Hogarth Press.

Freud, S. (1923) The Ego and the Id, Standard edn, vol. 19, London: Hogarth Press.

Freud, S. 1973 'Why War?' In Maple, T. and Matheson, D. W. (ed.) Aggression, Hostility, and Violence - Nature or Nurture? New York. Holt, Rinehart, and Winston, Inc. Pp. 16-27.

Friedlander K. The psychoanalytical approach to juvenile delinquency. New York: International Universities Press; 1945.

Hokanson J, Burgess M. The effects of three kinds of aggression on vascular processes. Journal of Abnormal and Social Psychology. 1962;64:446-449.

K. Shivakumara at al., (2014) Frustration Potential of Delinquent Adolescents, British Journal of Education, Society \& Behavioral Science. Vol, 4(5): 581-591.

Kuppens, S., Grietens, H., Onghena, P., and Subramainian. S. V. (2008). Individual and classroom variables associated with relation aggression in elementary school aged children. Human development and health, 46(6), 639-660.

Lagerspetz, J., Bjorkqvist, K., Berts, M., and King, E. (1982). Group aggression among school children in there school. Scandinavia Journal of Psychology, 23(1), 45-52.

Legerspetz, K., Bjorkquist, K., and Peltonen, T. (1988). Is indirect aggression typical of females? Gender differences in aggressiveness in 11 to 12 year old children. Aggressive Behaviour, 14 (6), 403-414.

Miller, N. E. (1941). The frustration and aggression hypothesis. Psychological Review, 48(4), 337-342.

Robinson SM. Juvenile delinquency: Its nature and control. New York: Holl Rinchart \& Winston; 1961.

Rosenzweig, and Saul Dr. (1976). Aggressive behaviour and the Rosenweig picture-frustration study. Journal of Clinical Psychology, 32 (4), 885-891.

Seashore \& Bavelar.(1942). A study of frustration in children. Genetic psychology, 61, 279-314.

Trevithick, P. (2008) 'Revisiting the knowledge base of social work: a framework for practice', British Journal of Social Work, vol. 38: 1212-1237.

Trevithick, P. (2012) Social Work Skills and Knowledge: A Practice Handbook, 3rd edn. Maidenhead: Open University Press.

\section{Websites:}

www.cmseducatio.org

www.googlescholar.com

www.shodhaganda.com 